SAND2004-4193

Unlimited Release

Printed November 2004

\title{
Failure Analysis for the Dual Input Quad NAND Gate CD4011 Under Dormant Storage Conditions
}

\author{
N. Robert Sorensen \\ Corrosion, Electrochemistry \& Cleaning Department
}

Sandia National Laboratories

P.O. Box 5800

Albuquerque, NM 87185-0888

\begin{abstract}
Several groups of plastic molded CD4011 were electrically tested as part of an Army dormant storage program. For this test, parts had been in storage in missile containers for 4.5 years. Eight of the parts (out of 1200) failed the electrical tests and were subsequently analyzed to determine the cause of the failures. The root cause was found to be corrosion of the unpassivated $\mathrm{Al}$ bondpads. No significant attack of the passivated $\mathrm{Al}$ traces was found. Seven of the eight failures occurred in parts stored on a preposition ship (Jeb Stuart), suggesting a link between the external environment and observed corrosion.
\end{abstract}




\section{Table of Contents}

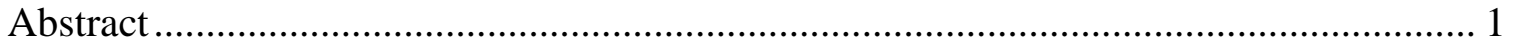

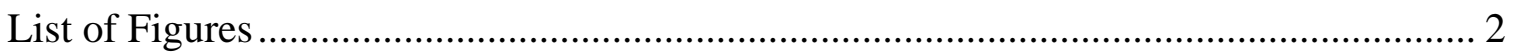

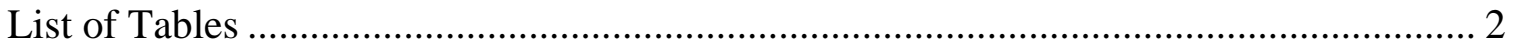

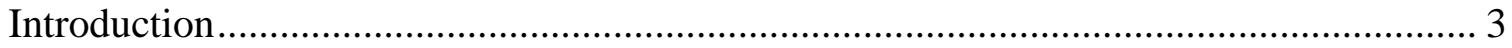

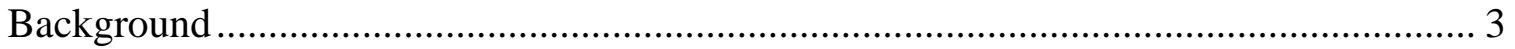

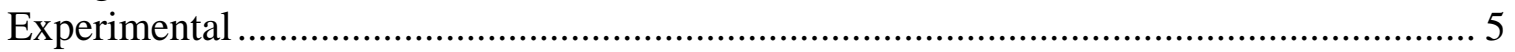

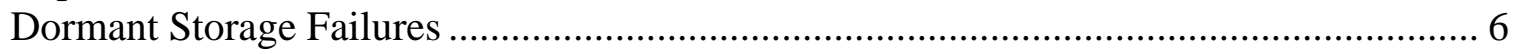

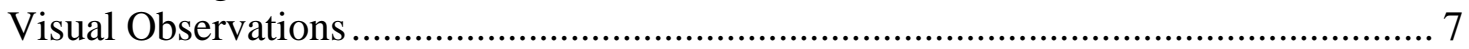

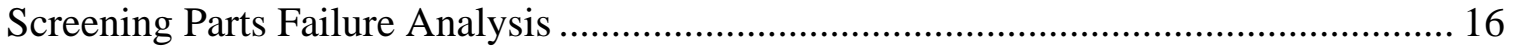

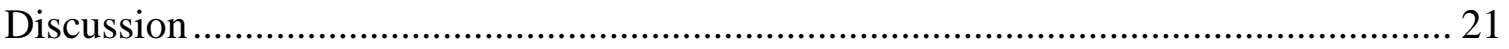

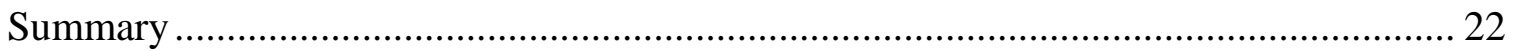

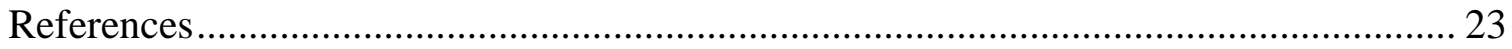

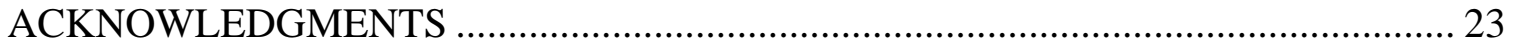

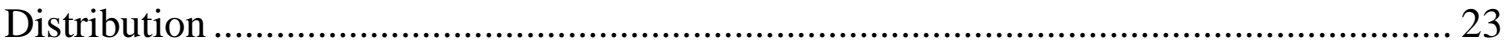

\section{List of Figures}

Figure 1. Pin assignments for and photograph of CD-4011 ........................................ 4

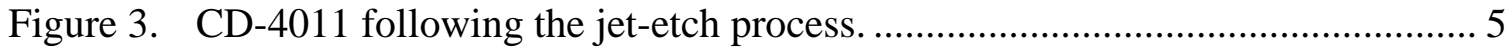

Figure 4. Optical micrographs of Al bondpads for CD-4011 S/N N001. ....................... 8

Figure 5. Optical micrographs of Al bondpads for CD-4011 S/N N003. ...................... 9

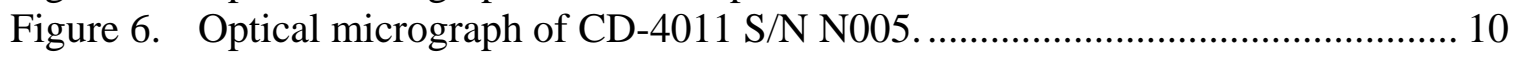

Figure 7. Optical micrographs of Al bondpads for CD-4011 S/N H005.. .................... 11

Figure 8. Optical micrographs of Al bondpads for CD-4011 S/N T182....................... 12

Figure 9. Optical micrographs of Al bondpads for CD-4011 S/N S089...................... 13

Figure 10. Optical micrographs of Al bondpads for CD-4011 S/N S196...................... 14

Figure 11. Optical micrographs of Al bondpads for CD-4011 S/N M069...................... 15

Figure 12. Optical micrographs of Al bondpads for CD-4011 S/N 008.. ...................... 16

Figure 13. Optical micrographs of Al bondpads for CD-4011 S/N H59.. ...................... 17

Figure 14. Optical micrographs of Al bondpads for CD-4011 S/N H65.. ....................... 18

Figure 15 Optical micrographs of Al bondpads for CD-4011 S/N H43.. ...................... 19

Figure 16. Optical micrographs of Al bondpads for CD-4011 S/N N38.. ...................... 20

Figure 17. Optical micrographs of Al bondpads for CD-4011 S/N P43......................... 21

\section{List of Tables}

Table 1: History of CD-4011 Parts During Dormant Storage Test ................................. 4

Table 2: Failure Location Based on Visual Observation \& Electrical Test Results......... 7

Table 3: Observations of CD-4011 Parts From Initial Part Screening ........................... 17 


\section{Introduction}

As the military moves to use commercial off the shelf (COTS) and, particularly plastic encapsulated microelectronics (PEMs), concern over the long-term reliability of these parts has increased. These parts are more susceptible to environmental degradation due to their construction. Traditional military electronics have been packaged in ceramic hermetic packages (CHP) which prevent the introduction of moisture from the external environment. PEMs, on the other hand, use injection molded plastic as the environmental barrier. While the plastic is effective at preventing the ingress of liquid water, moisture permeation through the plastic is quite rapid, resulting in its introduction to the die surface, particularly if voids or defects exist above the die and/or lead frame. The result of this moisture transport through the plastic can result in corrosion of the metallization features on the die.

The consumer electronics industry, which uses the vast majority of PEMs parts, has little interest in their stability under long-term dormant storage conditions. Consumer electronics are used regularly, and are thus turned on and off frequently. Heating which occurs when the parts are powered drives moisture from the die surface and dries the part. Military electronics, on the other hand, are normally stored unpowered for long periods. Once activated, they must function properly the first time. The result of these conditions is a sensitivity to degradation under dormant storage conditions. Currently, no validated accelerated aging conditions have been established for dormant storage conditions. Data from real field exposure studies provide insight into failure mechanisms, rates, and the amount of risk involved in using PEMs in military electronics.

\section{Background}

A dormant storage study to assess the long-term reliability of plastic encapsulated microlectronic (PEM) parts was undertaken in 1994. One of the test vehicles chosen for the project is a CD4011 (quad input dual NAND gate). It is a CMOS integrated circuit constructed with $\mathrm{N}$ - and P-channel enhancement mode transistors. The package is dual in-line package (DIP) and is soldered to the printed wiring board using plated through hole technology. Figure 1 shows the pin assignments for this device along with a photograph of one of the parts. The CD4011 is a common device, produced by many semiconductor manufacturers. It is a standard plastic part that uses $\mathrm{Al}$ bondpads and $\mathrm{Au}$ bondwires. The Al traces are covered with a passivation layer. For this study, the parts were soldered onto an edge card connector (one part per card) and placed in storage boxes in Hellfire missile containers. The missile containers were stored in the same locations and under the same conditions as Hellfire missiles. They were deployed to army bases that included Eglin, Ft Greely, Yuma and Redstone Arsenal (RSA). The parts at Redstone were originally deployed on the Jeb Stuart (preposition ship), but when it was retired, the containers were moved to RSA. The cards were grounded during storage to prevent electrical damage, but were unpowered, thus representing dormant storage conditions. 


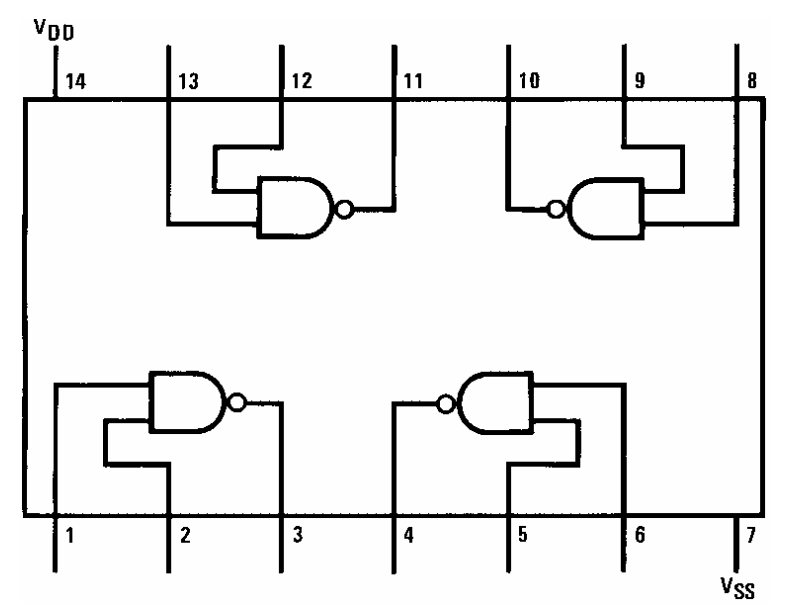

Figure 1. Pin assignments for and photograph of the CD4011 2-input quad NAND gate device used in dormant storage program.

Originally, electrical testing was performed by Rome Laboratories (through the $3^{\text {rd }}$ year of storage). They have since dropped out of the project and the electrical testing has since been performed at Analytic Solutions Inc. (ASI) through a contract with Sandia National Laboratories.

The history of the parts is presented in Table 1 and gives information about the exposure time. The exposure time is the actual time in the missile storage containers. Total time is also shown, which includes time spent during testing and transit. Thus, when these parts were electrically tested, the field exposure time was 4.5 years and the total time was 7.3 years. Both numbers are likely to be important, as the conditions during shipping and testing may not vary widely from those experienced during storage.

Table 1: History of CD-4011 Parts During Dormant Storage Test

\begin{tabular}{rrrrl} 
Date Start & Date End & $\begin{array}{c}\text { Elapsed } \\
\text { Time (days) }\end{array}$ & $\begin{array}{c}\text { Elapsed } \\
\text { Time (yrs) }\end{array}$ & Comments \\
\hline $12 / 1 / 94$ & $1 / 1 / 96$ & 936.00 & 1.08 & 1st Year of Storage \\
$1 / 1 / 96$ & $5 / 1 / 96$ & 121.00 & 0.33 & 1st Annual Retest and Failure Analysis \\
$5 / 1 / 96$ & $3 / 1 / 97$ & 304.00 & 0.83 & 2nd Year of Storage \\
$3 / 1 / 97$ & $5 / 1 / 97$ & 61.00 & 0.17 & 2nd Annual Retest and Failure Analysis \\
$5 / 1 / 97$ & $8 / 1 / 97$ & 92.00 & 0.25 & New Test Set Correlation Studies \\
$8 / 1 / 97$ & $3 / 1 / 99$ & 577.00 & 1.58 & 3rd Year of Storage \\
$3 / 1 / 99$ & $12 / 1 / 99$ & 275.00 & 0.75 & 3rd Annual Retest and Failure Analysis (Test \\
& & & & should have been Aug 98) \\
$1 / 1 / 00$ & $1 / 1 / 01$ & 366.00 & 1.00 & 4th Year of Storage \\
$1 / 1 / 01$ & $1 / 1 / 02$ & 365.00 & 1.00 & 4th Annual Test - Sandia Labs \\
$1 / 1 / 02$ & $4 / 11 / 02$ & 100.00 & 0.27 & $\begin{array}{l}\text { Parts Received @ 5400 From Sandia Labs } \\
4 / 11 / 02\end{array}$ \\
& $4 / 17 / 02$ & 6.00 & 0.02 & $\begin{array}{l}\text { Parts Carried to Mark Ambrose at 7855 for } \\
\text { shipment to storage locations. }\end{array}$ \\
$5 / 2 / 02$ & $10 / 29 / 02$ & 180.00 & 0.49 & $\begin{array}{l}\text { Parts back in storage (RSA, Eglin, Ft. Greely, } \\
\text { and Yuma). }\end{array}$ \\
\hline Exposure time (days) & 1643.00 & 4.50 & \\
Total time (days) & 2663.00 & 7.30 &
\end{tabular}




\section{Experimental}

Parts that failed the electrical tests after verifying card alignment with the test fixture were dissected for failure analysis. The plastic was removed in the vicinity of the die using a jet-etch process with hot anhydrous nitric or sulfuric acid. Because the acid is anhydrous, it attacks the plastic but does no damage to the die, the Al metallization, or the Au bondwires. Parts were baked out at $125^{\circ} \mathrm{C}$ overnight prior to depotting to remove moisture from the plastic. If moist plastic is subjected to the jet-etch process, steam is created, introducing stresses that can damage the bondpads. In addition, the presence of moisture can result in corrosion of the bondpad during decapsulation. Figure 2 shows a CD-4011 following the jet-etch process. The die is readily visible along with the $\mathrm{Au}$ bondwires and Al bondpads. This process allows examination of the die surface and the bondpads, and provides the means to establish the cause of electrical failure.

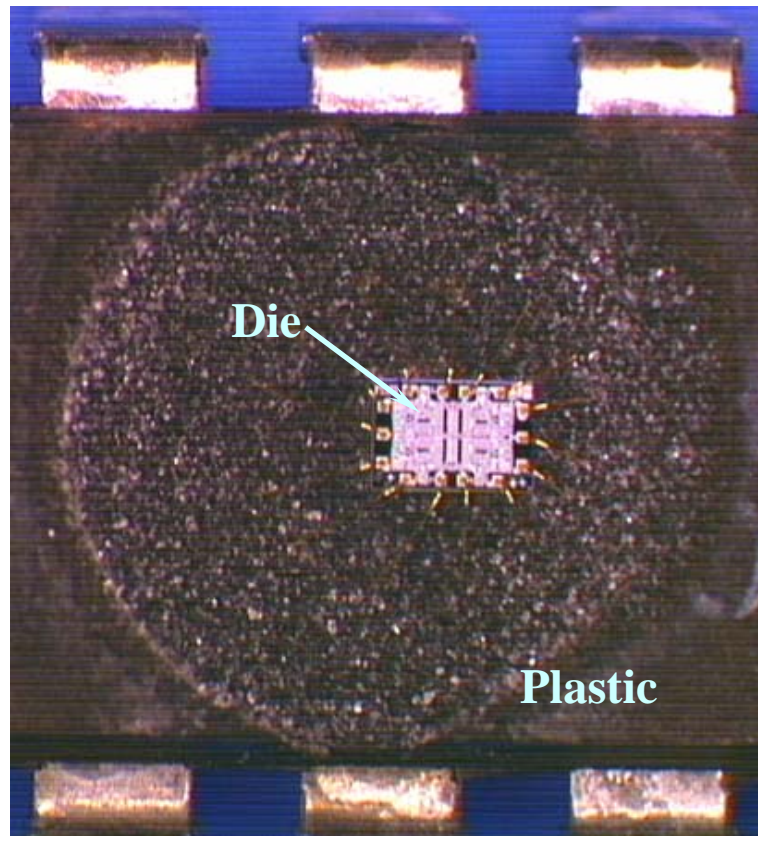

(a)

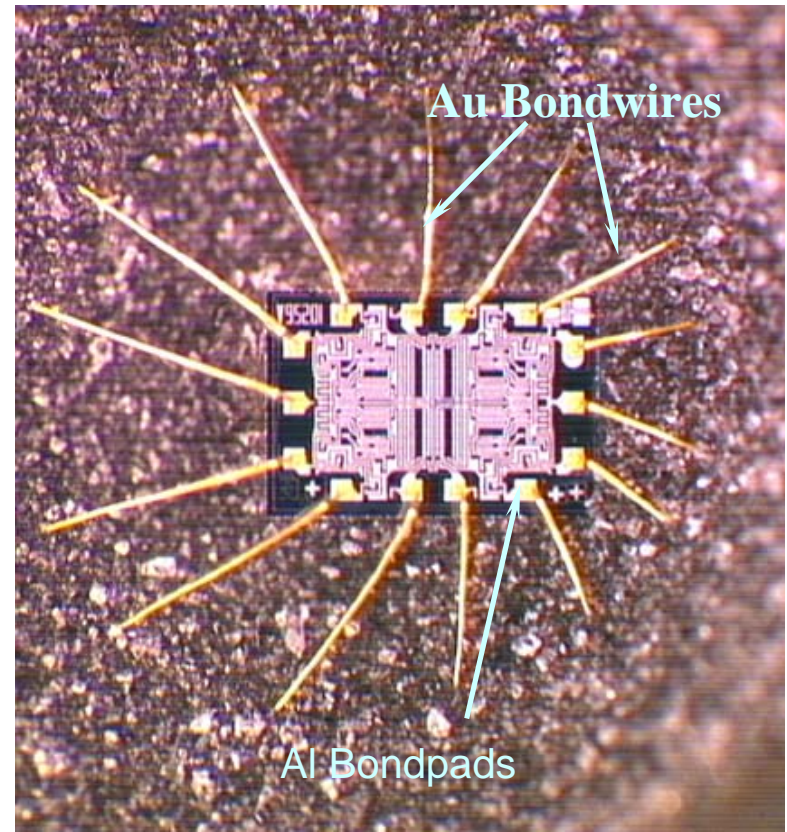

(b)

Figure 2. CD-4011 following the jet-etch process to remove the plastic encapsulant from the die surface.

Electrical testing was performed on an LTS 2020 automated tester using an adaptor that accepts the card containing the part. Special care was taken to align the contacts of each card with the tester socket (the contacts on several of the cards were misaligned relative to the card). The tester was programmed to perform parametric and functional testing of each part. All electrical tests were performed at room temperature. 


\section{Dormant Storage Failures}

Table 2 presents data for parts exhibiting electrical failure after accounting for misalignment of the edge card connector. In total, eight of the parts had confirmed electrical failures and were all examined for evidence of corrosion. It is interesting to note that seven of the eight failures occurred from a single storage location. (These parts were initially stored on the preposition ship, the USS Jeb Stuart. When it was retired, these parts were moved to Redstone Arsenal, Huntsville Alabama.) The number of failures associated with this group of parts suggests that they were exposed to a more aggressive environment. It is probable that elevated levels of humidity and/or temperature are responsible. The electrical failure was generally manifest as open circuits for one or more of the device leads. The failures appeared to occur at random locations rather than on the same pads for multiple devices. Associated with the electrical failures, corrosion of the bondpads was generally observed (in one instance - N005-5 - pins 1 through 13 were not visible after the jet etch process due to residual plastic on the die). As with the electrical data, corrosion was found on different pins, indicating that the design of the part does not determine the failure location. Importantly, corrosion was not generally observed on all bondpads, but was often confined to specific bondpads which varied from sample to sample. 
Table 2: Failure Location Based on Visual Observation \& Electrical Test Results

\begin{tabular}{|c|c|c|c|}
\hline Device & Location & Electrical Test Data & Jet Etch Results \\
\hline N 001-1 & Redstone* & Lots of failures no obvious trend & $\begin{array}{l}\text { Corrosion on Pins 1, 3, 4, 9, 12, } \\
\text { 13, 14(pwr) }\end{array}$ \\
\hline N 005-5 & Redstone* & Pin 1 open (input for pin 3) & Ok, could not see pins 1 - 13 \\
\hline N 003-3 & Redstone* & $\begin{array}{l}\text { Lots of failures - no obvious } \\
\text { trend }\end{array}$ & Corrosion on Pins 5(gnd), 6 \\
\hline H 005-5 & Redstone* & $\begin{array}{l}\text { Pins } 8 \text { and } 9 \text { open (inputs for pin } \\
10\end{array}$ & $\begin{array}{l}\text { Corrosion on Pins 1, 2, 3, 7, 8, 9, } \\
12,13,14(p w r)\end{array}$ \\
\hline T 182-4 & Redstone* & $\begin{array}{l}\text { Output pins } 11,(12 \text { and } 13 \\
\text { inputs) and } 4 \text { (5 and } 6 \text { input) } \\
\text { wrong state }\end{array}$ & $\begin{array}{l}\text { Corrosion on Pins 6, } 7 \text { (can't see } \\
8 \text { - 12) }\end{array}$ \\
\hline S 089-2 & Redstone* & $\begin{array}{l}\text { Output pins 11, (12 and } 13 \\
\text { inputs) wrong state }\end{array}$ & $\begin{array}{l}\text { Corrosion on all pins except } 11 \\
\text { and } 14\end{array}$ \\
\hline S 196-4 & Redstone* & $\begin{array}{l}\text { Pin } 2 \text { open (input for output pin } \\
\text { 3) }\end{array}$ & Corrosion on all pins \\
\hline M 069-2 & Eglin & $\begin{array}{l}\text { Pins 1, } 5,8 \text { (inputs for pins } 3,4 \text {, } \\
\text { 10) open }\end{array}$ & Corrosion on Pins 5, 6, 9 \\
\hline \multicolumn{4}{|c|}{$\begin{array}{l}\text { * Parts were originally stored on the Jeb Stuart. They were transferred to Redstone when the } \\
\text { Jeb Stuart was de-comissioned. }\end{array}$} \\
\hline
\end{tabular}

\section{Visual Observations}

All of the parts that exhibited electrical failure were examined optically for evidence of corrosion. Figure 3 shows optical images of part S/N N001 following the decap process. Electrical testing resulted in many failures with no obvious trends being established. Corrosion was observed on many of the bondpads (1, 3, 4, 9, 12, 13 \& 14). Three of the bondpads are shown (9,12, and 13). Attack of the bondpad is visible, although the $\mathrm{Al}$ has not been entirely consumed. In addition, corrosion has progressed beneath the passivation layer at the edge of the bondpad. No evidence of trace corrosion was found.

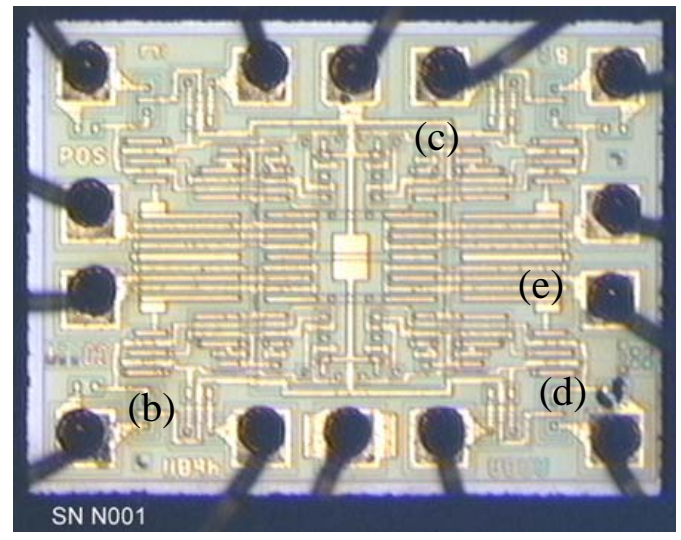

(a)

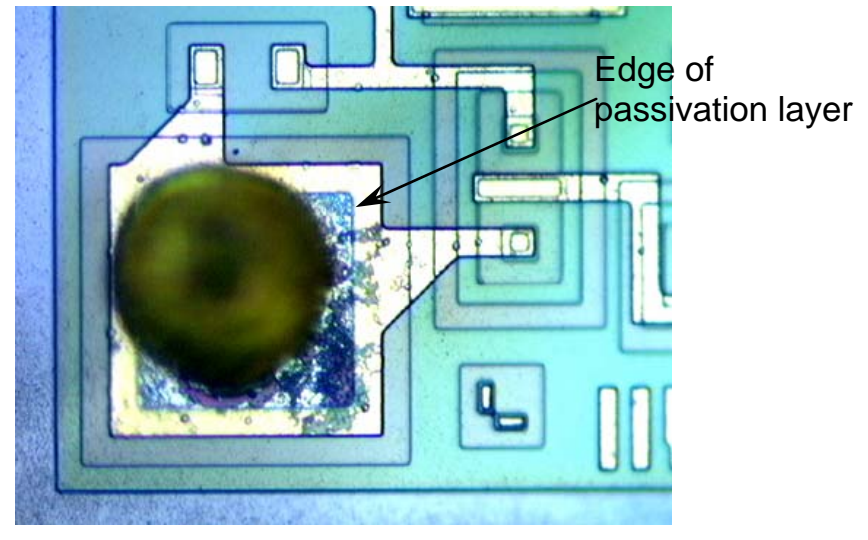

(b) 


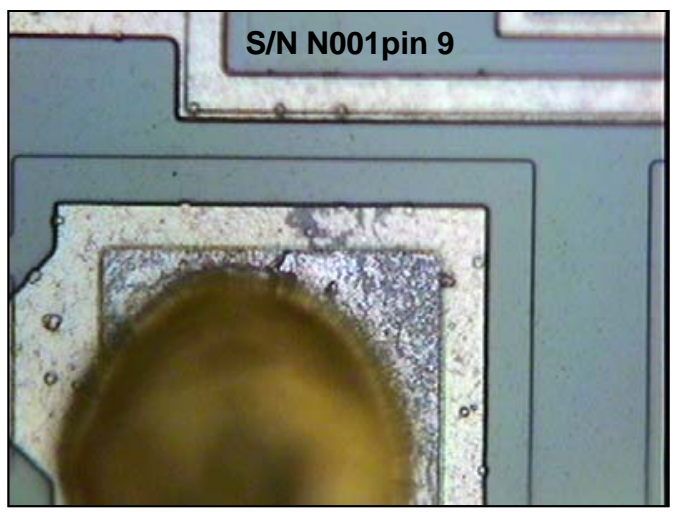

(c)

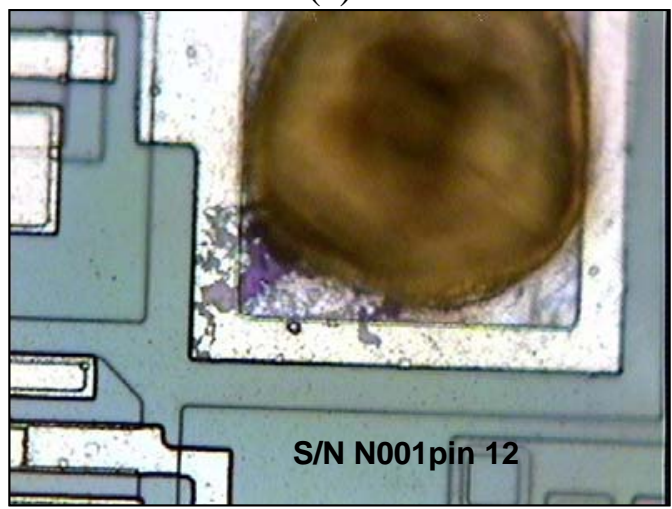

(e)

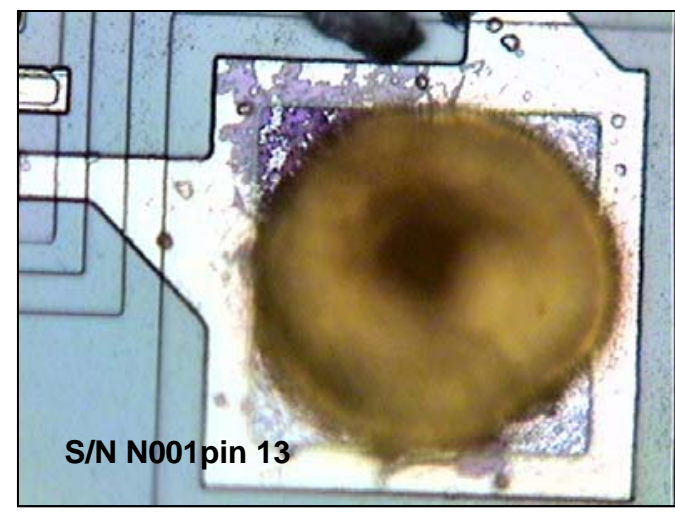

(d)

Figure 3. Optical micrographs of Al bondpads for CD-4011 S/N N001. Note attack of Al and progression of attack below the passivation layer. 
Figure 4 shows images of device N003. Electrically, numerous failures were observed, with no obvious trends. Following the de-cap process corrosion was observed on bondpads 5 and 6 . In this case, the bondpads were almost completely consumed. Corrosion products are visible on the die surface. No evidence of trace corrosion was found.

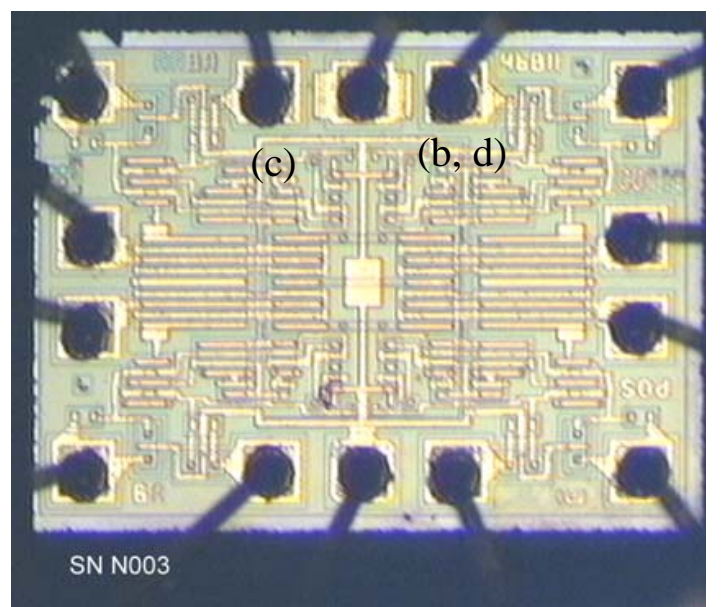

(a)

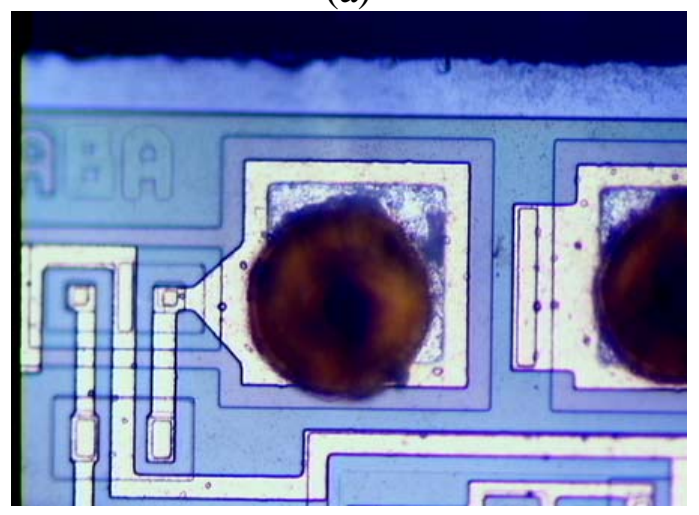

(c)

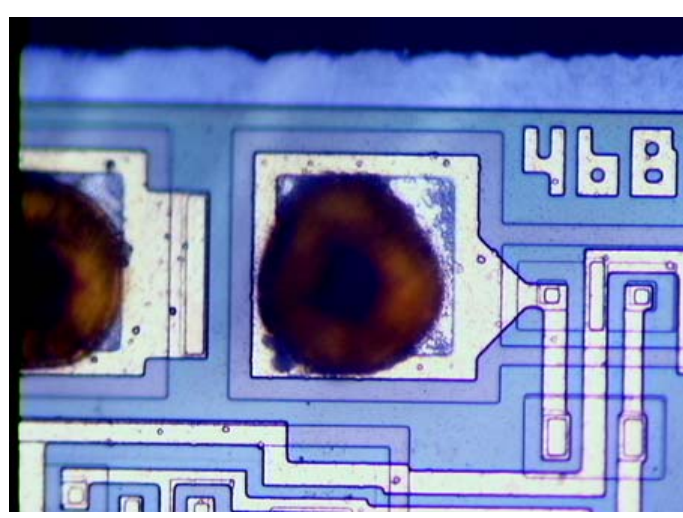

(b)

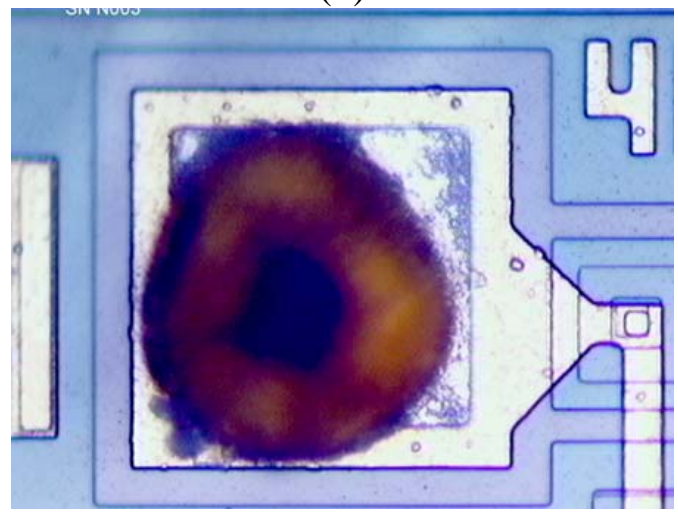

(d)

Figure 4. Optical micrographs of Al bondpads for CD-4011 S/N N003. Note attack of Al and progression of attack below the passivation layer. 
Device S/N N005 exhibited an open circuit on pin 1. Images from this device are shown in Figure 5. During the de-cap process, the epoxy was not completely removed from the die surface. Thus, several of the wirebonds were not visible for optical evaluation. Corrosion is visible on several of the bondpads. In general, it stops at the passivation layer, but some undercutting of the passivation layer is visible (c). No evidence of trace corrosion was seen.

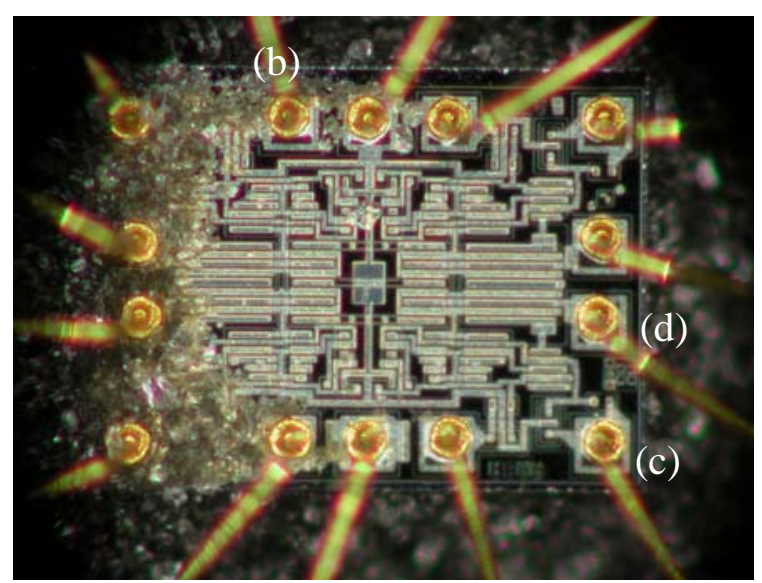

(a)

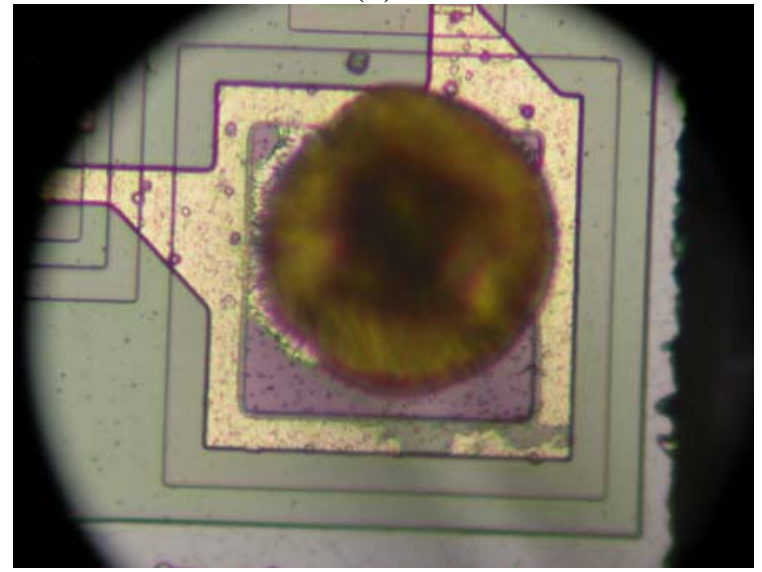

(c)

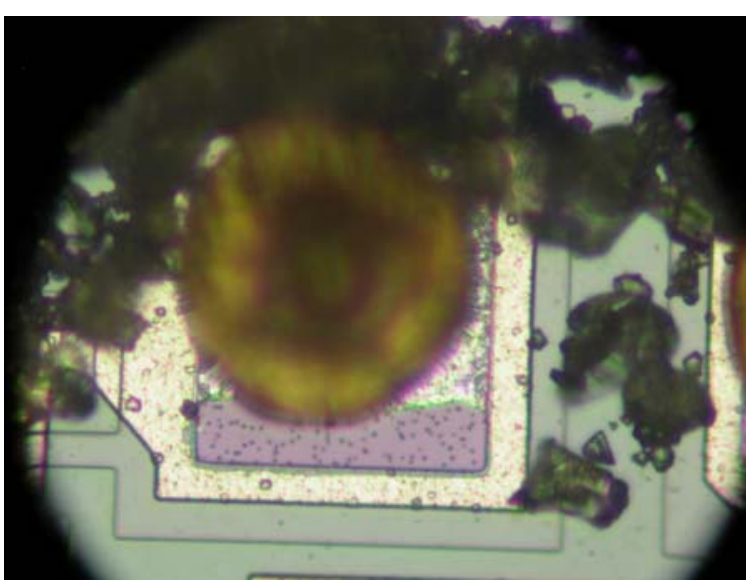

(b)

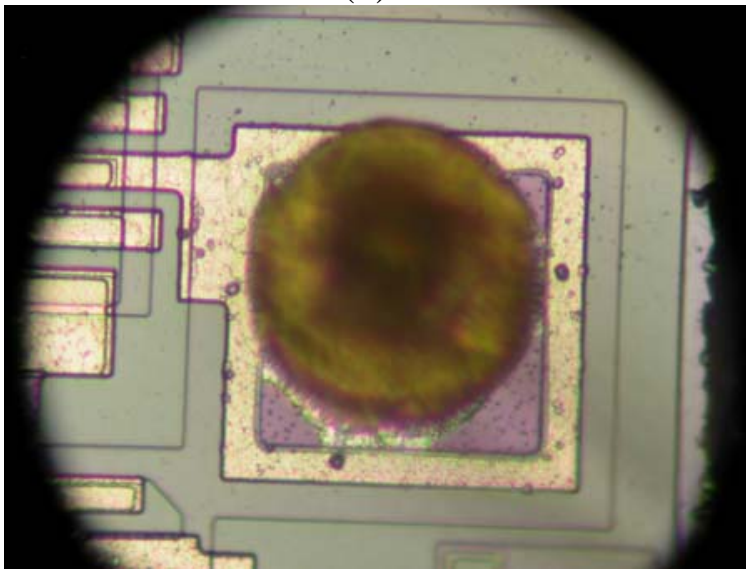

(d)

Figure 5. Optical micrograph of CD-4011 S/N N005. Labels on the image in (a) indicate location for individual bondpads imaged in (b)-(d). 
Sample S/N H005 exhibited opens at pins 8 and 9 during electrical testing. Optical microscopy (Figure 6) revealed corrosion on pins 1,2,3,7,8,9,12,13 and 14. As seen in the figure, extensive attack of the bondpad was observed. Corrosion products are visible on the die surface. Although only two of the bondpads indicated open circuit, many more were corroded which would likely lead to additional open circuits in the future. No evidence of trace corrosion was seen.

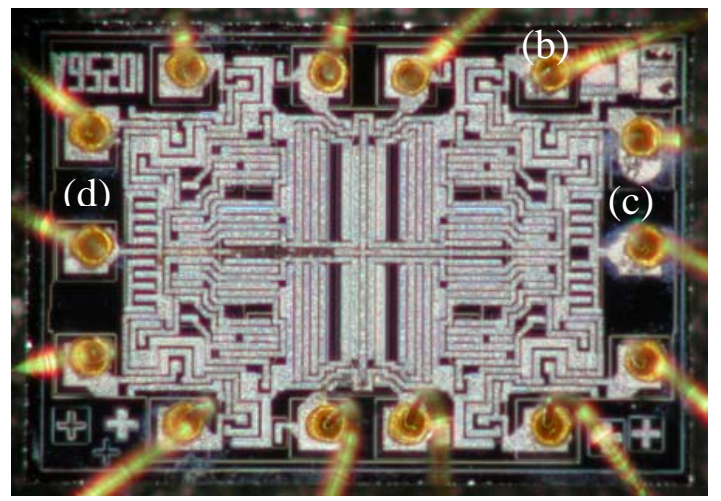

(a)

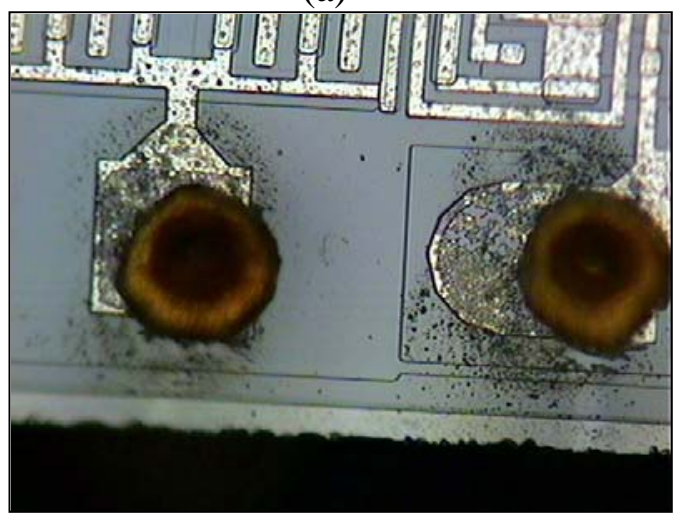

(c)

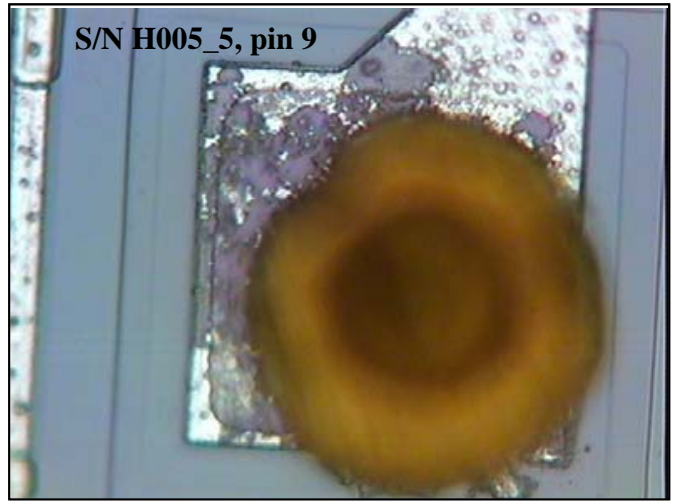

(b)

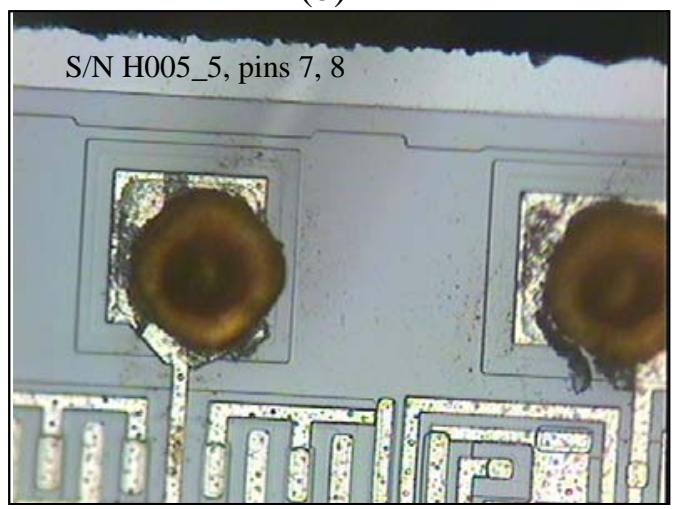

(d)

Figure 6. Optical micrographs of Al bondpads for CD-4011 S/N H005. Extensive attack of the bondpad and corrosion products on the die surface can be seen. Labels on the image in (a) indicate location for individual bondpads imaged in (b)-(d). 
Figure 7 shows images from S/N T182. In electrical testing, several of the leads were in the wrong state. Visual analysis indicated corrosion of bondpads associated with pins 6 and 7 . Those connected to pins 8 through 12 were obscured by residual epoxy, and thus, were not visible. In general, the die is very clean and shows no evidence of trace corrosion.

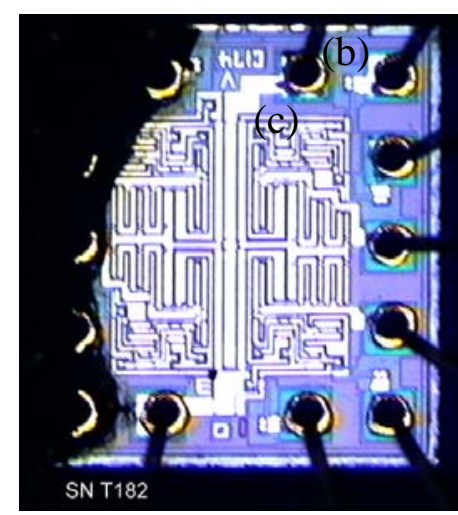

(a)

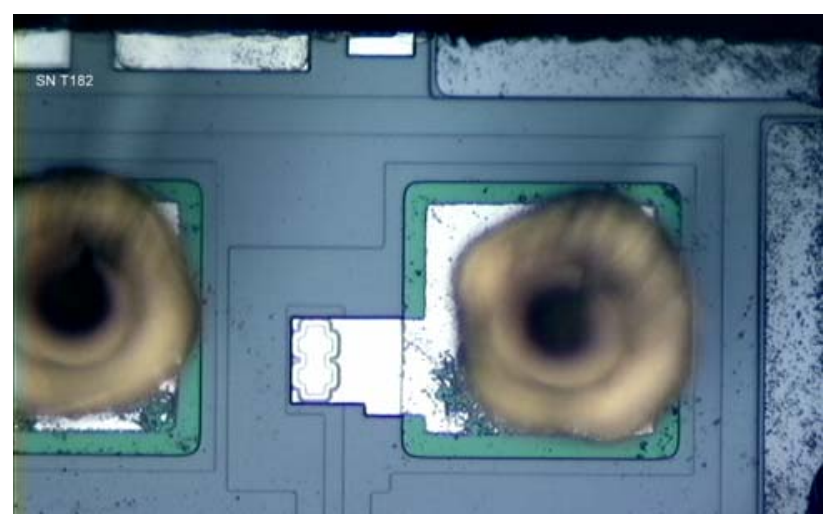

(b)

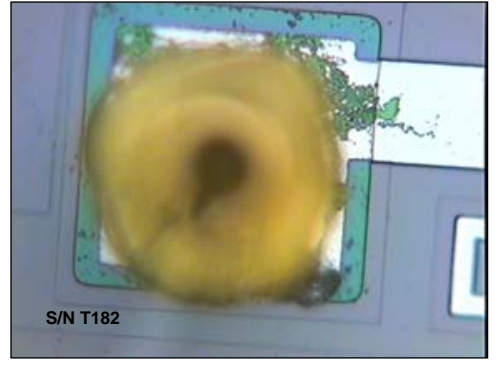

(c)

Figure 7. Optical micrographs of Al bondpads for CD-4011 S/N T182. Attack of the bondpad can be seen with corrosion progressing beneath the passivation layer. Pins 6 and 7 were affected. Labels on the image in (a) indicate location for individual bondpads imaged in (b)-(c). 
Figure 8 shows device S/N S089. Electrical testing resulted in output pin 11 in the wrong state. Corrosion was found on all pins except 11 and 14. The extent of attack ranged from slight to severe. In some instances, the bondpad was almost completely consumed. No evidence of trace corrosion was seen.

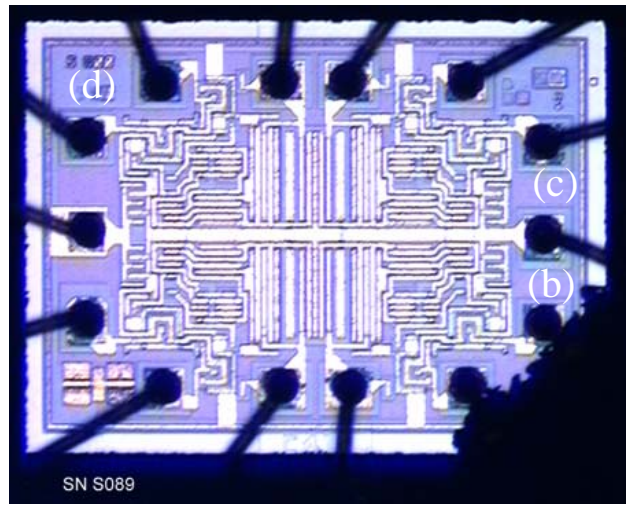

(a)

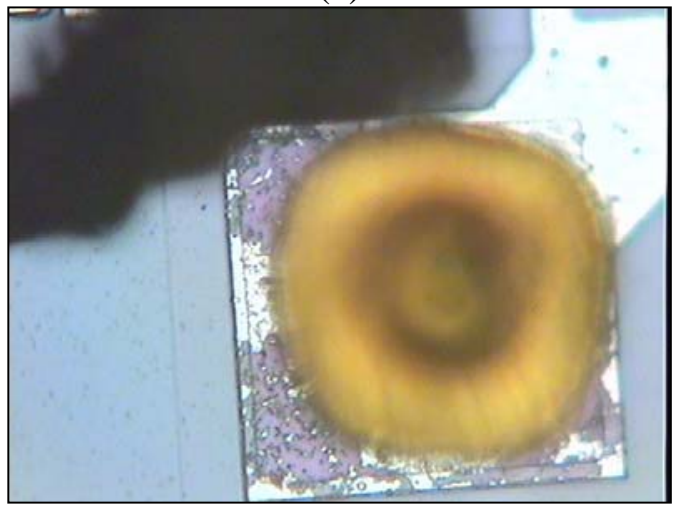

(c)

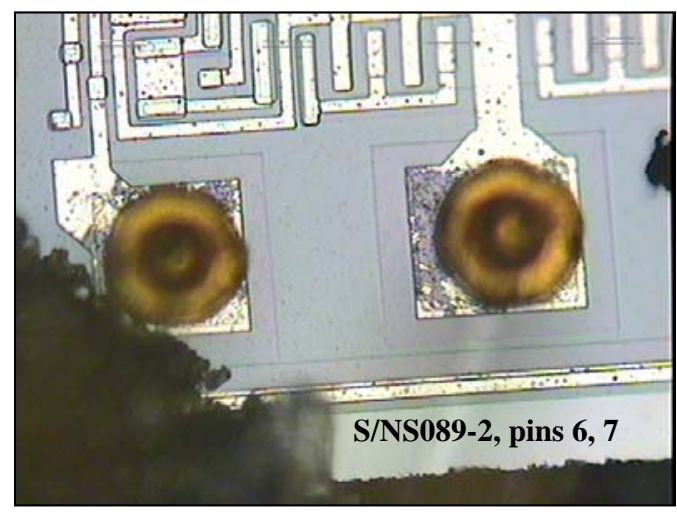

(b)

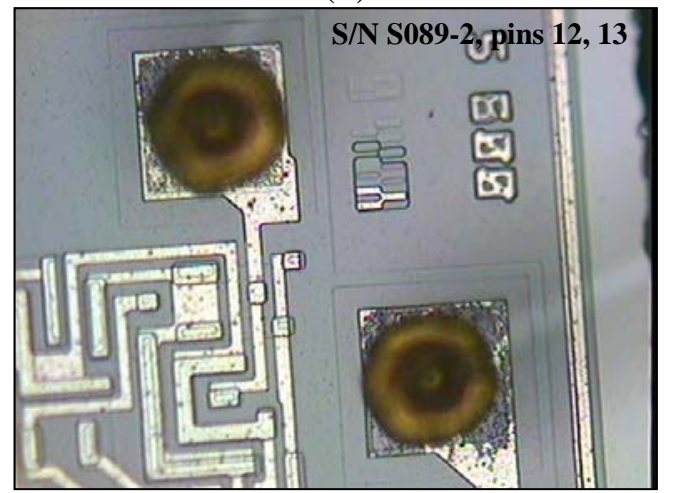

(d)

Figure 8. Optical micrographs of Al bondpads for CD-4011 S/N S089. Extensive attack of the bondpad can be seen with corrosion progressing beneath the passivation layer. Pins 6, 7, 12, and 13 were attacked. Labels on the image in (a) indicate location for individual bondpads imaged in (b)-(d). 
Figure 9 shows images from S/N S196. Pin 2 tested open during electrical testing. Corrosion was seen on all of the bondpads. The bondpad attack is visible, even on the low magnification image of the entire die. On some bondpads, the Al bondpad appeared to be totally consumed. In many areas, corrosion products are visible on the die surface around the bondpad.

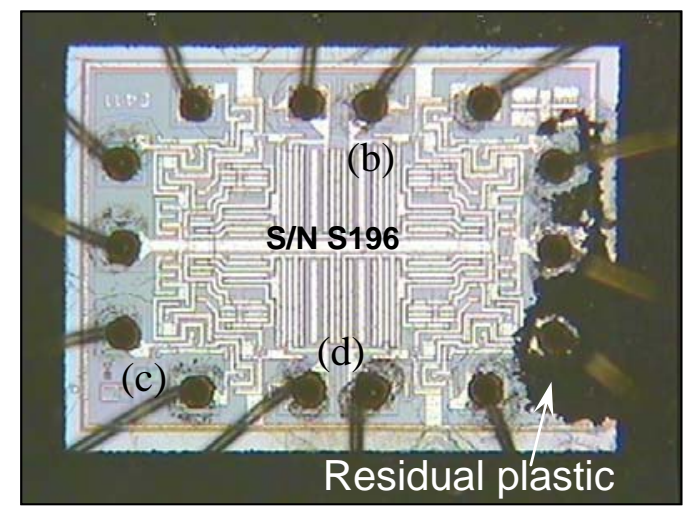

(a)

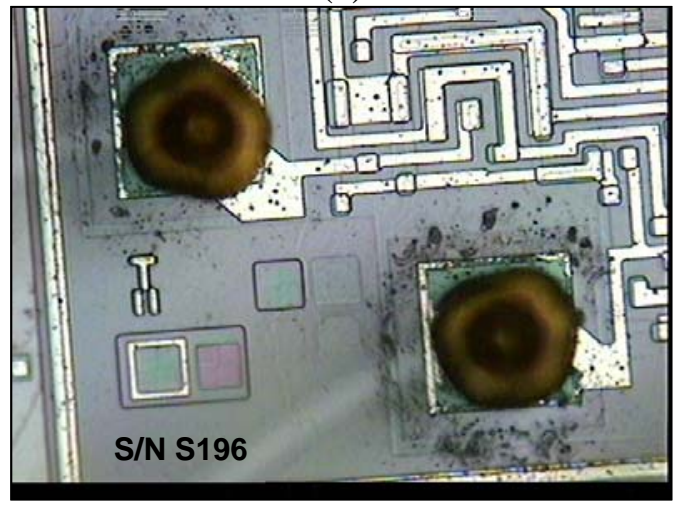

(c)

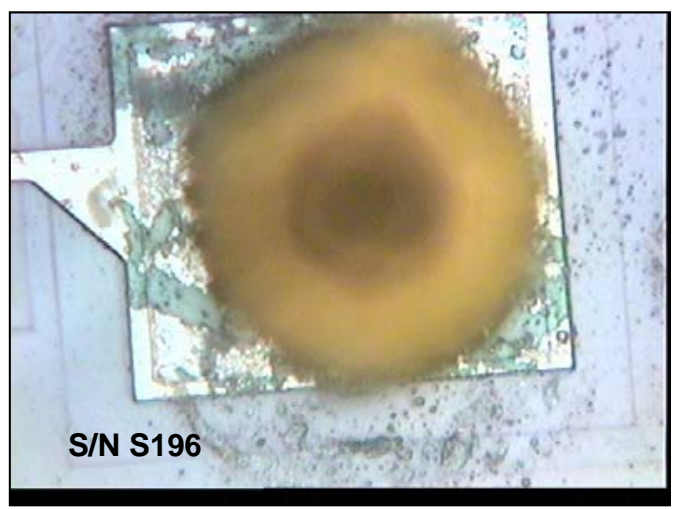

(b)

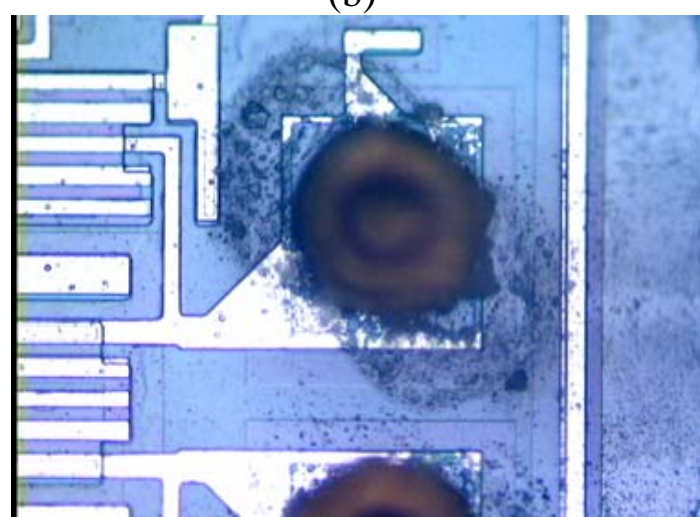

(d)

Figure 9. Optical micrographs of Al bondpads for CD-4011 S/N S196. All bondpads exhibited some degree of attack. Labels on the image in (a) indicate location for individual bondpads imaged in (b)-(d). 
Figure 10 shows data for S/N M069. Pins 1,5, and 8 tested open. Corrosion was observed on pins 5,6 , and 9 . The extent of visible corrosion was considerably lower on this device. In all cases, the majority of the Al bondpad was intact. The attack appeared to be concentrated around the edge of the gold ball. Otherwise, the die was clean, with no evidence of trace corrosion.

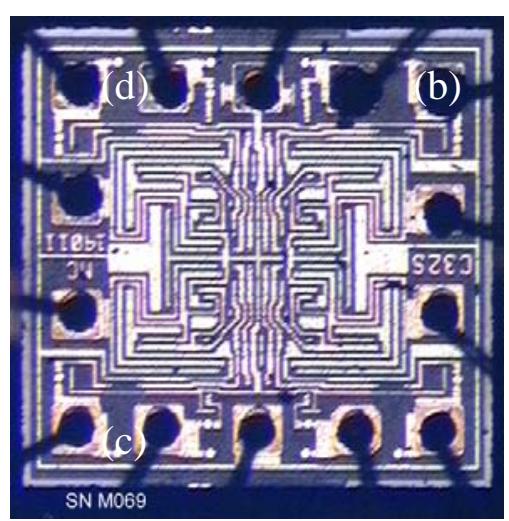

(a)

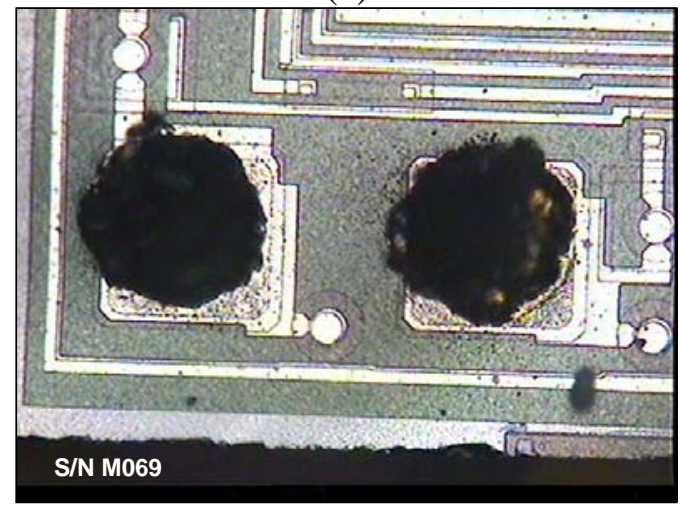

(c)

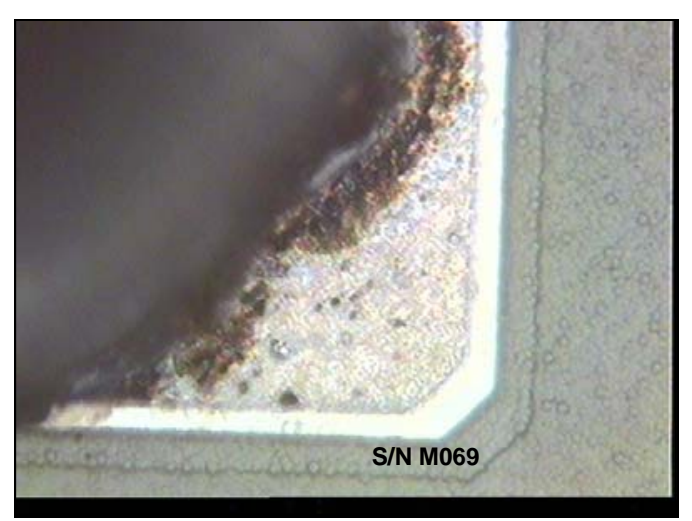

(b)

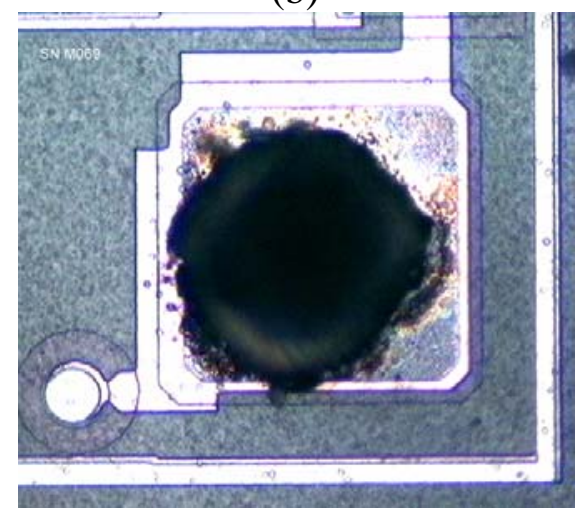

(d)

Figure 10. Optical micrographs of Al bondpads for CD-4011 S/N M069. Minor attack of the bondpad is visible. In addition, the rough material at the edge of the ball bond suggests formation of intermetallic compounds (ref. 1). Labels on the image in (a) indicate location for individual bondpads imaged in (b)-(d). 
The last device examined was labeled SN 008. At this point the source of this part and the manufacturer is unknown. Based on the appearance of the die, it appears to be a Toshiba part. During testing and analysis, the identification was lost. Thus, the electrical response is unknown. This part exhibited extensive corrosion at several of the bondpads. In some instances, the entire $\mathrm{Al}$ bondpad had been consumed, with corrosion products visible on the die surface. Because the identification of this device is still unknown, it was not included in the failure rate data. During the next electrical testing sequence, an effort will be made to identify the source of SN 008.

(b)

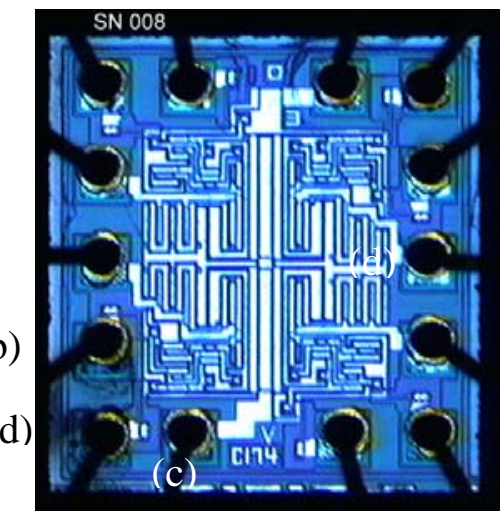

(a)

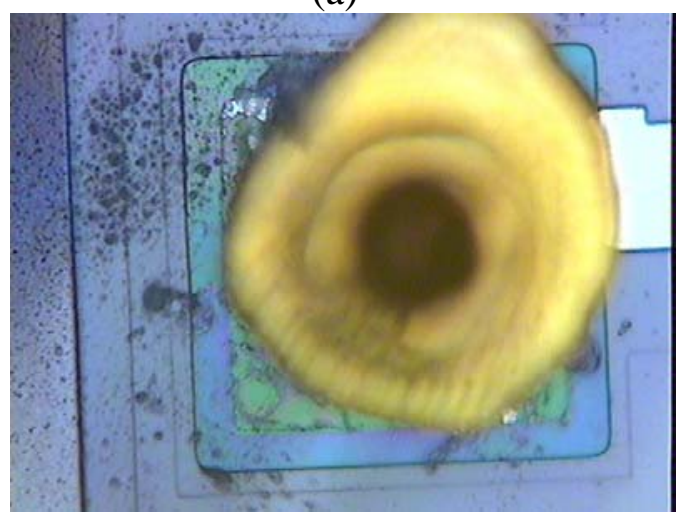

(c)

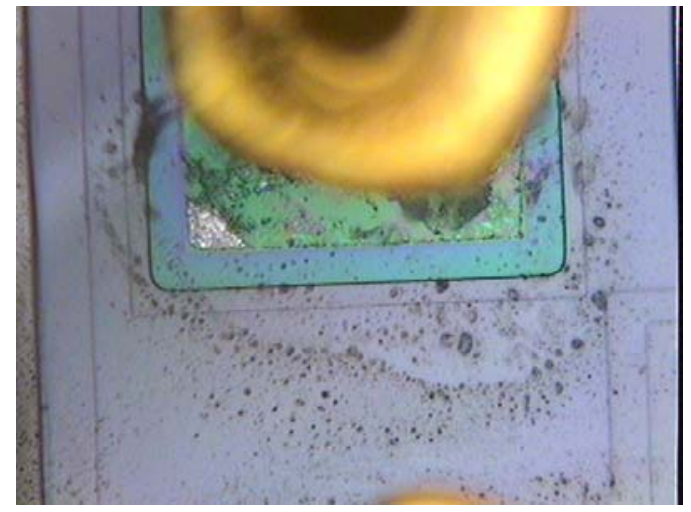

(b)

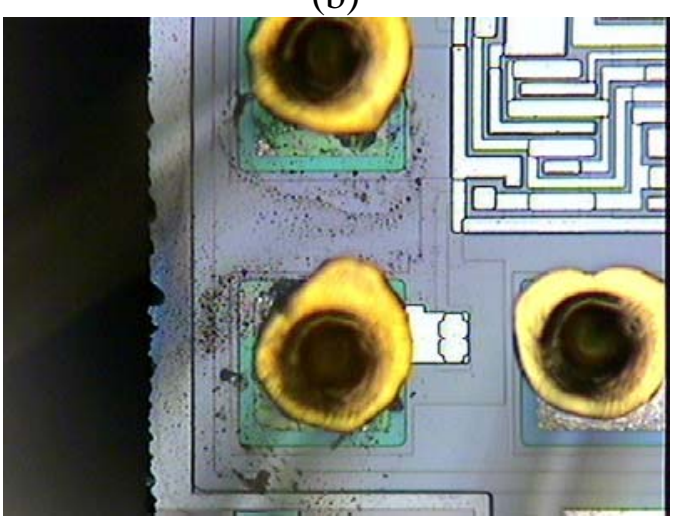

(d)

Figure 11. Optical micrographs of Al bondpads for CD-4011 S/N 008. Severe attack of the bondpad is visible. In addition, corrosion products can be seen on the die surface. Labels on the image in (a) indicate location for individual bondpads imaged in (b)-(d).

\section{Screening Parts Failure Analysis}

In addition to the parts from dormant storage, a group of parts that failed during incoming inspection and screening was obtained from Redstone Arsenal. Failure analysis of these parts was performed to determine if failure modes were the same for the two populations. No electrical testing was performed at Sandia on these parts, so no specifics about electrical failures are available. All that is known is that they failed during incoming or during part screening at Redstone. 
Table 3 presents the electrical and de-cap results for this group of parts. Ten parts were evaluated. Five exhibited corrosion of the bondpads. The other 5 parts failed due to other reasons, predominantly overstress (electrical).

Table 3: Observations Based on Visual Examination of CD-4011 Parts From Initial Part Screening

\begin{tabular}{|l|l|l|}
\hline Manufacturer & \multicolumn{2}{c|}{ S/N } \\
\hline Harris & 59 & $\begin{array}{l}\text { Bond pad corrosion on pin 1, no visible damage (NVD) } \\
\text { otherwise }\end{array}$ \\
\hline Harris & 27 & Overstress on pin 7, ground \\
\hline Harris & 65 & Slight pad corrosion on pins 5, 6 \\
\hline Philips & 57 & Pin 7, ground pad fused open \\
\hline Toshiba & 44 & No visible damage \\
\hline Philips & 43 & Pin 1 corrosion \\
\hline Harris & 1 & Overstress on pin 7, ground \\
\hline Harris & 2 & Overstress on pin 7, ground \\
\hline NSC & 38 & Corrosion on multiple pads \\
\hline Harris & 43 & Corrosion on multiple pads \\
\hline
\end{tabular}

Figure 12 shows the die and bondpad for the Harris 59 device. Slight corrosion is seen on the bondpad, with no other evidence of attack.

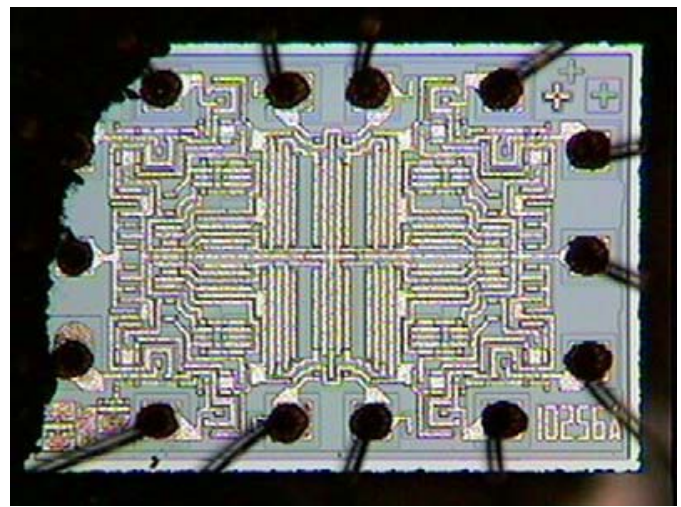

(a)

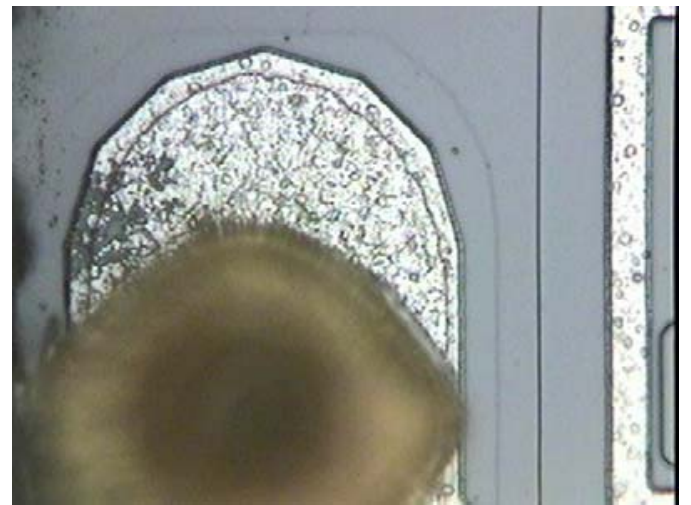

(b)

Figure 12. Optical micrographs of Al bondpads for CD-4011 S/N H59. The die is generally healthy with a small amount of bondpad corrosion seen on pin 1. 
Figure 13 shows results for Harris SN 65. Attack was seen on pin 5 and 6. Although the attack was not extensive, it is possible that it was concentrated at the $\mathrm{Au} / \mathrm{Al}$ interface, resulting in isolation of the Au wire and electrical open at that point.

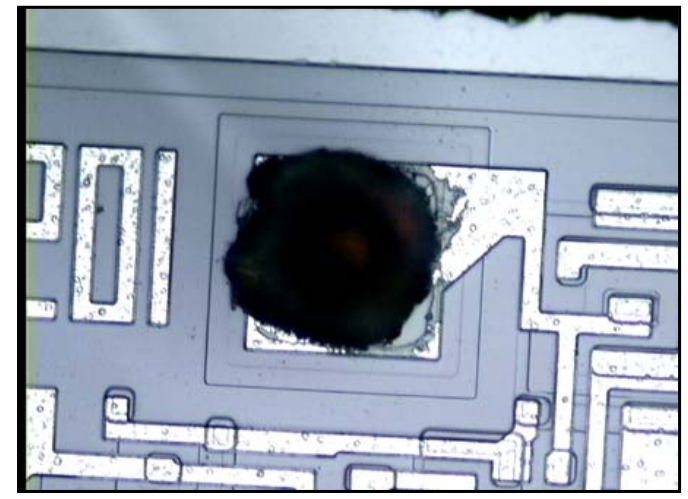

(a)

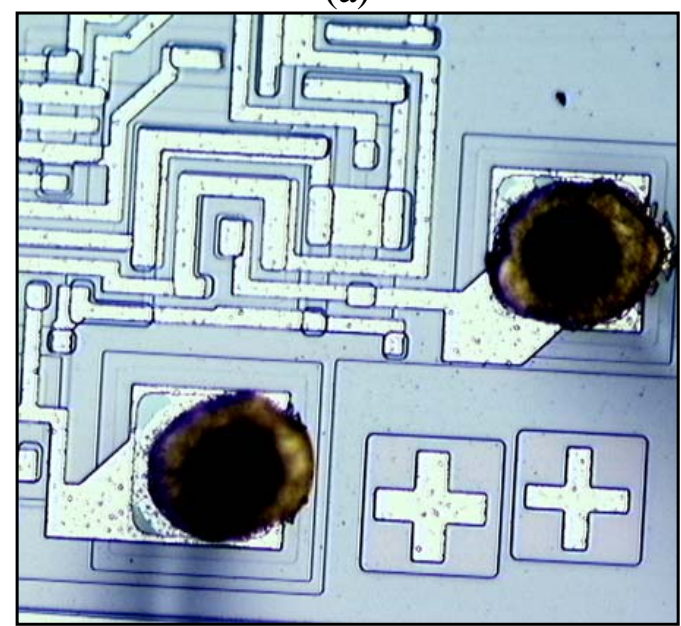

(c)

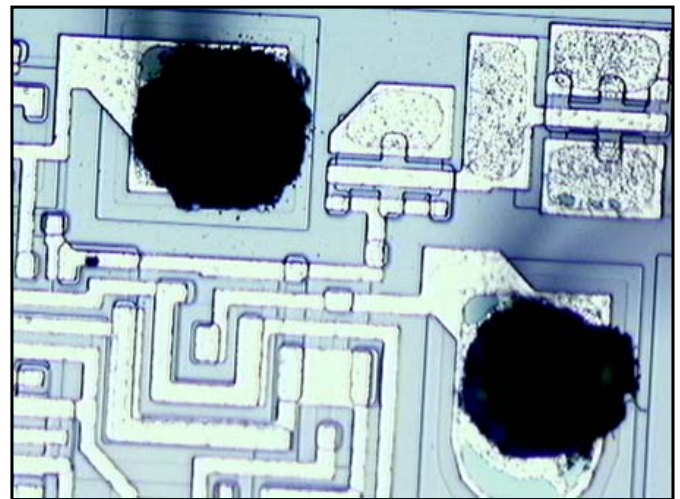

(b)

Figure 13. Optical micrographs of Al bondpads for CD-4011 S/N H65. The die is generally healthy with a small amount of bondpad corrosion seen on several bondpads. 
Figure 14 presents results from Harris 43. Corrosion was observed on multiple bondpads. The attack is quite severe, with substantial Al missing from several of the bondpads. In some cases (e.g. Figure 14c), corrosion has progressed from the bondpad into the trace (beneath the passivation layer) connected to the bondpad.

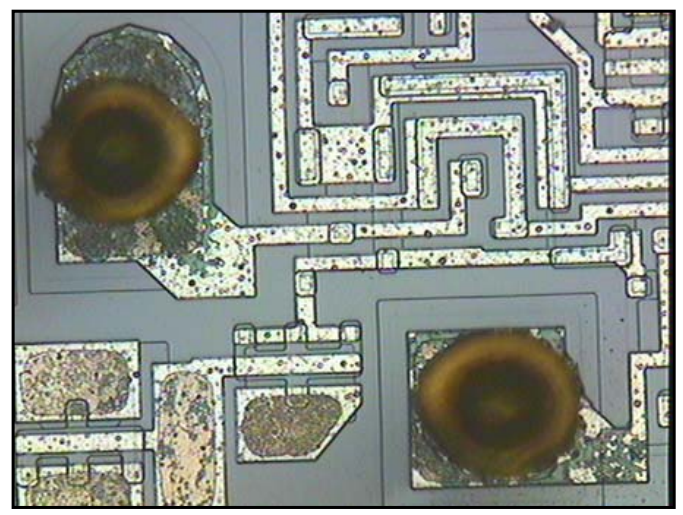

(a)

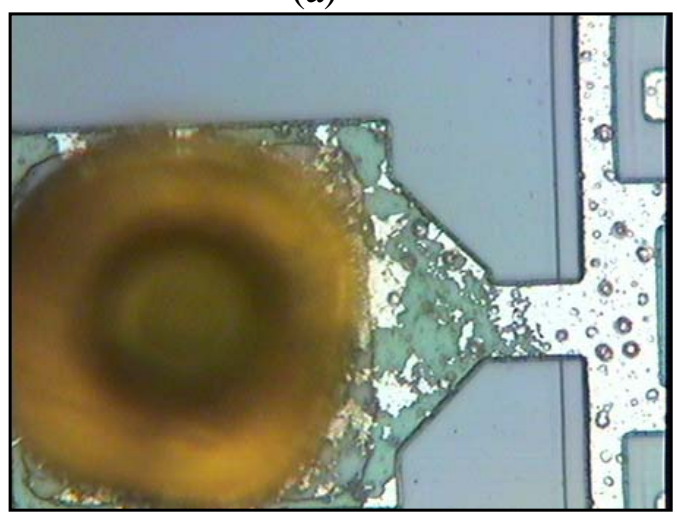

(c)

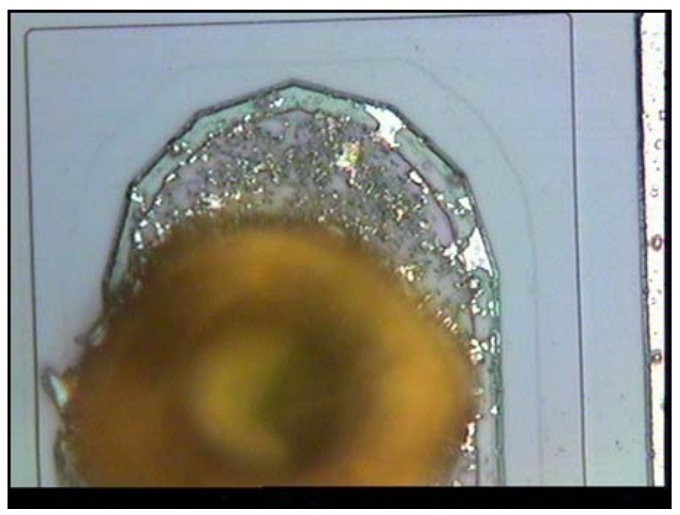

(b)

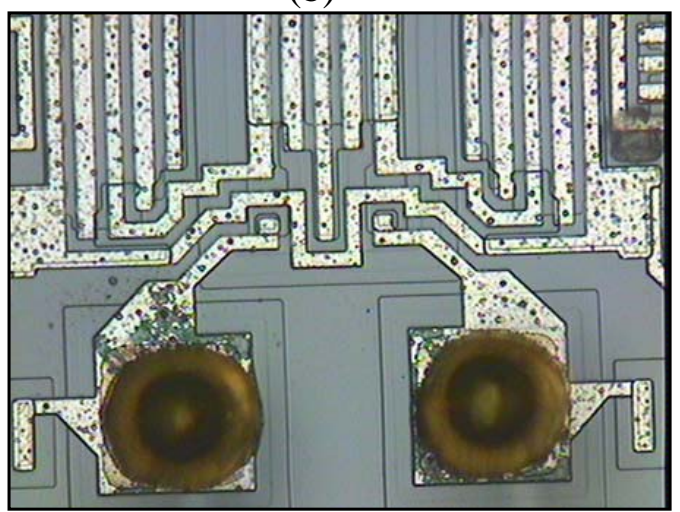

(d)

Figure 14 Optical micrographs of Al bondpads for CD-4011 S/N H43. Substantial corrosion can be seen on several bondpads, with some evidence of attack of the Al traces. 
Figure 15 shows results from National 38. Corrosion was observed on multiple bondpads. In some instances, it penetrated further beneath the passivation layer and attacked the adjacent Al. The extent of attack is certainly significant enough to result in electrical failure of the part. No attack of the traces was observed.

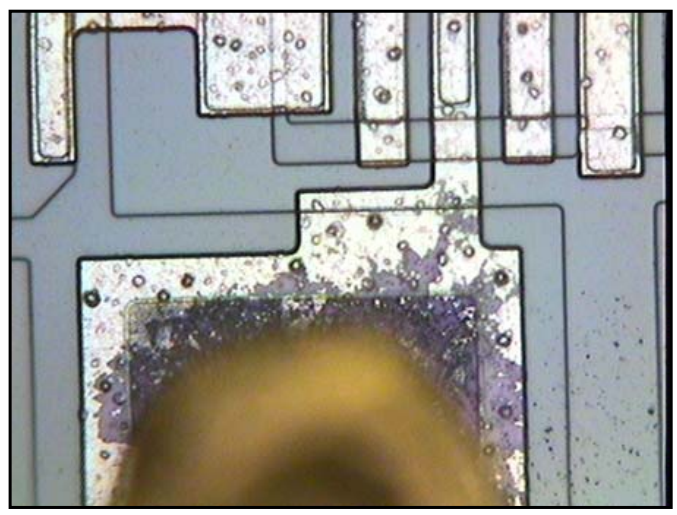

(a)

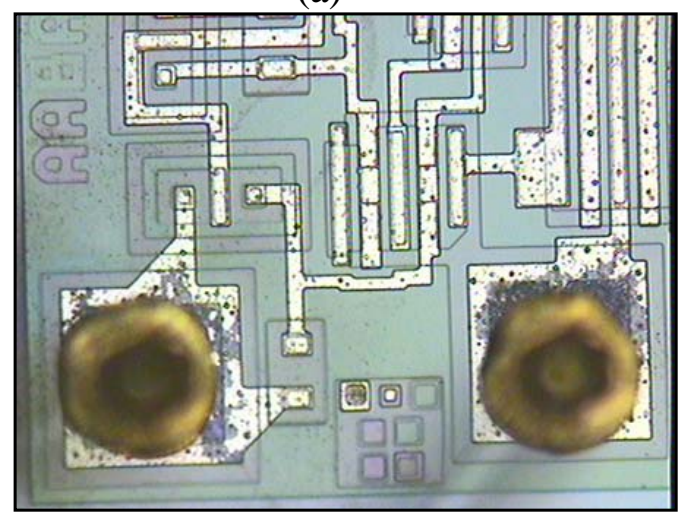

(c)

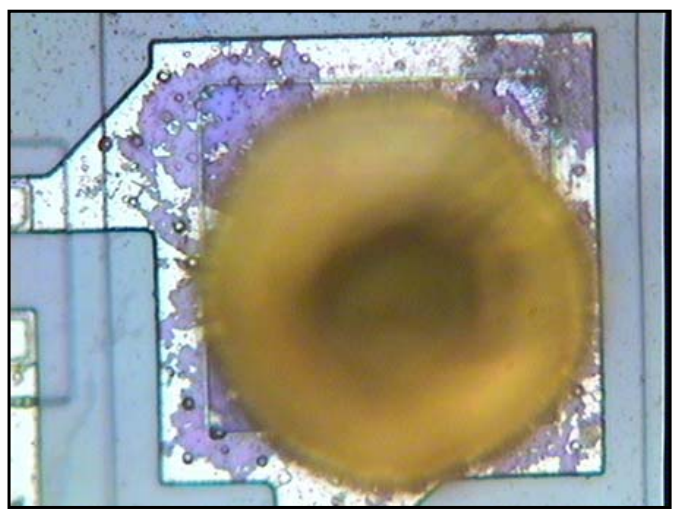

(b)

Figure 15. Optical micrographs of Al bondpads for CD-4011 S/N N38. Substantial corrosion can be seen on several bondpads. 
Figure 16 shows micrographs for Philips 43. Corrosion was observed on pin1. Significant attack of the bondpad can be seen. Other bondpads did not appear to be corroded. In addition, there was no evidence of trace corrosion.

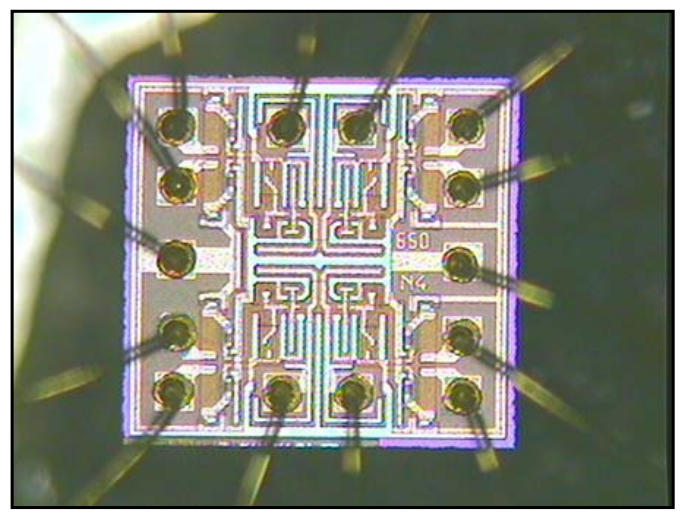

(a)

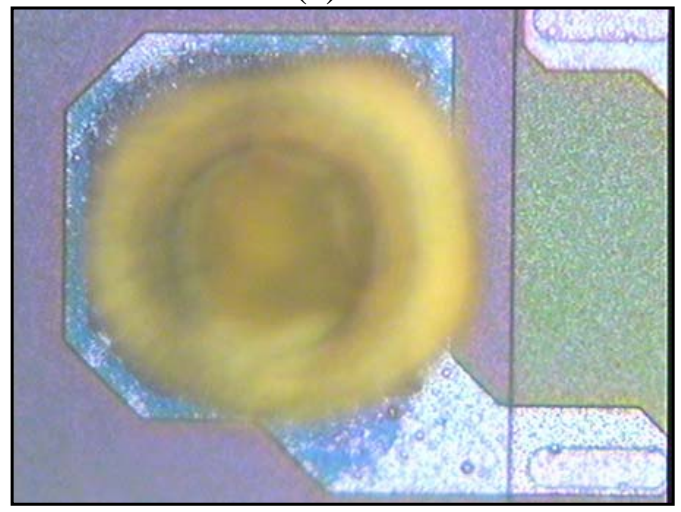

(c)

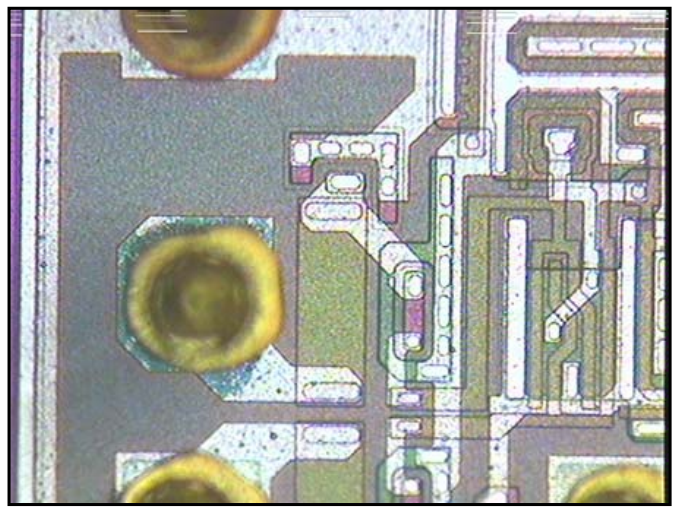

(b)

Figure 16. Optical micrographs of Al bondpads for CD-4011 S/N P43. Die is generally healthy. Some attack can be seen on pin 1.

\section{Discussion}

It is clear that corrosion of the $\mathrm{Al}$ bondpads was responsible for the electrical failure of several of the CD4011 parts. In general, the attack was limited to the bondpad itself. In some instances, corrosion was found beneath the passivation layer adjacent to the bondpad, but it was never observed to progress very far into the die interior. No attack of the passivated $\mathrm{Al}$ traces was observed. Thus, it is clear that the lack of passivation on the bondpads is a primary factor in corrosion of these devices. For bondpad corrosion to occur, both moisture and halogen (primarily chloride) contamination are required. We have experimental data showing that moisture alone will not cause corrosion of the $\mathrm{Al}$ bondpads (ref. 2). Based on our studies and results from industry, there is no evidence that contaminants can be transported through the plastic (ref. 3). Thus, it is likely that contaminants were present when the part was injection molded. The fact that not all of the bondpads were attacked suggests that the contamination was localized to specific locations rather than being found generally across the die surface. 
Looking at the data from the dormant storage program, there is clearly a correlation between storage location and failure rate. All but one of the failures occurred in parts originally stored on a preposition ship and then transferred to Redstone Arsenal. These data imply an environmental influence on the corrosion process. Certainly, a correlation with humidity is expected if sufficient chloride is present on the bondpad. Higher levels of humidity result in larger quantities of moisture available for reaction at the $\mathrm{Al}$ surface. This is consistent with expected ship-board environments, where the average humidity level is expected to be higher than at a land-based storage facility (e.g. Yuma, Arizona).

An evaluation of the failure data leads to some interesting observations. If the entire population of parts from all locations is treated as a single group (all storage locations combined), the failure rate is $8 / 1200$ or $0.67 \%$. If, however, the individual storage locations are considered to be unique, the failure rate for parts stored at Redstone is 7/300 or $2.3 \%$, a much more significant failure rate. This supports the idea that the external environment plays a significant role in the degradation of plastic parts. These are the first failures observed during testing. As shown in Table 1, parts were returned to storage on 1/1/00 following the year 3 electrical testing. Up to that time, no electrical failures had been observed. The storage time prior to that testing was about 3.5 years and the total time since the start of the test was 4.25 years (including time spent in shipping and electrical testing). Thus, failures were observed only after 7.3 years (4.5 years in actual storage).

One issue that derives from the current failures is the extent of compromised parts. It is certainly possible that all of the "defective" parts have failed. On the other hand, it is likely that other parts exist, with either lesser amounts of contamination or smaller moisture transport rates. If so, additional failures should be observed in the future. Unfortunately, by moving the parts to Redstone, the external environment has been modified, likely slowing the corrosion process. Therefore, future evaluations of these parts are essential.

The extent and appearance of corrosion was similar for both groups of parts examined (field failures and acceptance test failures). In both cases, corrosion was generally restricted to the unpassivated bondpad. This suggests that the product acceptance testing being performed by AMCOM is accelerating failure of these parts without changing the failure mechanism. This is consistent with the idea that contamination is introduced during manufacturing and/or production and the only additional element required for corrosion is moisture. Based on the failure analysis, the acceptance tests implemented by AMCOM forced moisture through the plastic and caused the corrosion.

\section{Summary}

A few general observations can be made from the results of these studies. In general, these parts appear to be quite robust. The failure rate is low, but for high reliability electronics, it is still significant. The corrosion process appears to be linked to external environment, with parts stored on the preposition ship (high humidity) exhibiting 
significantly higher failure rates. Both contamination \& moisture are needed for corrosion. The contamination was likely introduced during manufacture or packaging, but was certainly present when the parts were encapsulated. Corrosion was observed only on the bondpads. The traces, which are passivated, were essentially untouched. The importance of this type of dormant storage study is very clear. This failure mode (dormant storage failure) is not addressed by industry. In fact, this type of field exposure test is critical to determining the long-term dormant storage reliability of PEMs. Finally, it appears that the shipboard environment (Jeb Stuart preposition ship) provides a more aggressive storage environment than the standard land-based locations. It is unfortunate that the ship was retired from service, and that another, similar environment is not available for dormant storage tests.

\section{References}

1. D. R. Johnson, D. W. Palmer, D. W. Peterson, D. S. Shen, J. N. Sweet, J. T. Hanlon, K.A. Peterson, Mocroelectronics Plastic Molded Packaging, SANDIA Report, SAND97-0162, February 1997.

2. N. R. Sorensen, Unpublished work

3. CALCE report on chloride permeation through plastic encapsulants http://www.calce.umd.edu/members/database/pem/chapters/6_4_1.html

\section{ACKNOWLEDGMENTS}

This work was supported by a DoD/DOE MOU project. Michael Stricizh and Cliff Aldrich (Analytical Solutions Inc.) provided the electrical testing and sample de-capping. Sandia is operated by the United States Department of Energy under Contract DE-AC04-94AL85000. Sandia is a multi-program laboratory operated by Sandia Corporation, a Lockheed Martin Company, for the United States Department of Energy.

\section{Distribution}

$\begin{array}{lll}10 & \text { MS0888 } & \text { N. R. Sorensen, 1832 } \\ 1 & \text { MS0889 } & \text { P. T. Vianco, 1835 } \\ 1 & \text { MS1174 } & \text { J. T. Hitchcock, } \\ 1 & \text { MS0885 } & \text { R. J. Salzbrenner } \\ 1 & \text { MS0888 } & \text { J. W. Braithwaite } \\ 1 & & \text { Michael Strizich (ASI) } \\ 5 & & \text { Jessica Glover (AMCOM - RSA) } \\ 1 & \text { MS9018 } & \text { Central Technical Files, 8945-1 } \\ 2 & \text { MS0899 } & \text { Technical Library, 9616 } \\ 2 & \text { MS01612 } & \text { Review and Approval Desk, 9612 for DOE/OSTI }\end{array}$

